\title{
The Pragmatic Functions of Some Morphological Structures in Nzema Proverbs
}

\author{
Mohammed Yakub*, Yvonne A. A. Ollennu* \& \\ Cephas Delalorm** \\ University of Education, Winneba, Ghana* \\ University of Environmental and Sustainable Development, Ghana**
}

\footnotetext{
Mohammed Yakub (First \& Corresponding author)

Assistant Lecturer, Department of Akan-Nzema Education, College of Languages Education, University of Education, Winneba, Ghana

Email: yakubm88@gmail.com

Yvonne A. A. Ollennu (Co-author)

Senior Lecturer, Department of Ga-Gangme Education, College of Languages Education, University of Education, Winneba, Ghana

Email: ivonakwele@gmail.com

Cephas Delalorm (Co-author)

Lecturer, Department of General Studies, University of Environmental and Sustainable Development, Somanya, Ghana

Email: benmeerohm@gmail.com
}

Received 18 June, 2021; Revised 28 July, 2021; Accepted 17 August, 2021

Copyright (C) 2021 Language Research Institute, Sejong University Journal of Universal Language is an Open Access Journal. All articles are distributed online under the terms of the Creative Commons Attribution Non-Commercial License (http://creativecommons.org/licenses/by-nc/3.0) which permits unrestricted non-commercial use, distribution, and reproduction in any medium, provided the original work is properly cited. 


\begin{abstract}
The paper examines some morphological processes in the syntactic structure of proverbs in Nzema, a Kwa language spoken predominantly in the South-west part of the Western Region of Ghana, West Africa. The paper focuses on the pragmatic imports of such word formation processes in relation to how they contribute significantly to the understanding of the proverbs. The paper shows the prevalence of word formation processes, such as reduplication, inflections, derivations, lexical borrowing, and compounding in the construction of Nzema proverbs, which essentially help to conceptualise and infer the didactic messages that are communicated via the proverbs. Data were primarily gathered through participant and non-participant observations, including discussions and interviews with competent indigenous Nzema speakers. We extracted additional data from published sources, a compilation of Nzema proverbs and from other literary texts. The paper integrates the assumptions of Goddard's Ethnopragmatic Paradigm and Hockett's Item-and-Arrangement and Item-and-Process Models as theoretical underpinning.
\end{abstract}

Keywords: Nzema proverb, morphology, pragmatic, communication, culture, society

\title{
1. Introduction
}

Proverbs, which are believed to be a collective wisdom of a people, are characterised by metaphoric and pragmatic elements; carrying various contextual interpretations. According to Almutalabi \& Ameen (n.d.), a proverb is usually sightless unless pragmatics encompasses the entire vision of what, how, why, when and where it could be applied. This shows that, pragmatics, which deal with meaning that transcends what is said literally (Adesina 2015) is indispensable in the use and understanding of proverbs. Proverbs represent an essential aspect of sociocultural improvisation of any cultural group (Adesina 
2015). "Every culture has its rules of interaction and interpretation, and each also has rules for proverb construction and usage" (Lamidi 2008: 61). Stressing Lamidi's assertion, Adesina (2015) reports that every speech community has a set of rules and codes of behaviours which need to be obeyed for mutual cohesion; and that, proverbs make the people conform to such rules for enhancement of the transmission of tribal wisdom. Proverbs arise and are created as a result of natural occurrences; learning from the behaviours of animals, plants and other creatures within the ecosystem. Proverbs may also be 'crafted' as a result of human experiences and from the sociocutural activities of a particular group of people (Odebunmi 2006, Nyame \& Tomekyin 2018). Perhaps, this accounts for why Jegede \& Osoba (2019) inform us that the cultural background of a people can easily be traced through their proverbs.

According to Mbiti (1995), the language of proverbs has a rich vocabulary of combination of words and phrases, pictures, allusions and comparisons. This can suggest that word formation processes are important characteristics of the proverbial structure. Studies such as Mensah (2010), Bhuvaneswar (2012) and Aku-Sika (2016) have also shown that proverbs are not just constructed haphazardly; rather, there are grammatical (morphosyntactic) rules which the structure of proverbs follow in terms of the structural properties of a given language. For instance, in examining the morphosyntactic properties of Efik proverbs, Mensah (2010) identifies some morphological features such as inflections, derivations, reduplication and lexical borrowing as occurring at the lexical level in the syntactic structure of Efik proverbs. Mensah notes that Efik proverbs have a rich system of inflection, which underscores the agglutinative nature of the language. He explains this by postulating that most Efik proverbs have long polymorphic words in which each morpheme corresponds to a single 
lexical meaning or grammatical function. Mensah's work gives an insight that morphological properties are indispensable in the structure of proverbs which necessitates further investigation in another language and culture. Almutalabi \& Ameen (n.d.) also contend that the words which compose proverbs have several indications and vary in accordance with the used proverb in a given situation.

We find these observations insightful; and so they provide the motivation to also investigate as to whether Nzema proverbs at the lexical level are made up of specific word formation processes, which may not occur haphazardly, but may be present in the syntactic structures to perform crucial pragmatic roles in terms of the interpretations and understanding of the proverbs. Hence, the purpose of the current study is to identify and examine some morphological features in the structure of Nzema proverbs, and to highlight their pragmatic-communicative imports.

Having given a general introduction, the remaining parts of the paper fall under five (5) sections, described as follows: Section 2 provides an overview of some existing works on proverbs from pragmatics perspective. Section 3 highlights the sources, procedures and methods of data elicitation and how data were categorised for analysis. In section 4, some orientations on the theoretical frameworks deployed for the study are provided. Section 5 presents the data for analysis and discussion whereas the final section gives the summary of findings of the study.

\section{Previous Studies on Proverbs}

This section of the paper deals with the overview of some previous works which looked at pragmatic approaches to proverb studies. One 
of the most influential works by Ramírez (2015) employed the Relevance Theory espoused by Sperber \& Wilson $(1986,1995)$ in exploring the functions and uses of English and Spanish proverbs from a pragmatic point of view. The study examined and explained how proverbs are used to express intentions implicitly. It also showed the main functions of proverbs as to providing criticism, advice and warning; and as well how the ironical and metaphorical nature of proverbs often affects their understanding in discourse.

Adopting the Theory of Social Learning as a Reciprocal Determinism, Nwankwo (2015) discussed Igbo proverbs in the context of early communicative competence and social stability. Data for the study were primarily elicited through interviews with Igbo speakers between the ages of 45 and 65 years which focused on discussing the causes of conflicts and rate of moral decadence among youths and possible ways of restoring sanity to the society. The study aimed at examining proverbs as a viable means to ensuring proper upbringing and deterring conflict prone tendencies in the Igbo child. Nwankwo (2015) in his paper posits that Igbo proverbs are precise and incisive, and if appropriately inculcated to the intellectual and moral development of a child can serve as a tool to reprimand, discourage, instruct and correct or praise the growing child's derailing tendencies more intricately.

Another pragmatic analysis of proverbs was by Moshood (2016). The study examined 100 proverbs extracted from four literary works of Ola Rotimi (a Nigerian playwright). In the discussion, the author accounted for the didactic imports of the proverbs as portrayed through the socio-cultural values and worldview of the people being projected in the works of Ola Rotimi. The analysis further explored the relevant contexts of proverbial citations since "proverbs are essentially context-dependent" (Moshood 2016: 76). The study showed that both primary and secondary meanings are required to achieve the 
optimal interpretations of the proverbs under study. The primary level, as Moshood tells us, is needed for the basic meaning of the lexical items used in the construction of the proverbs whereas the secondary level is required to ensure the metaphoric and connotative imports of the messages expressed in the proverbs. Based on this observation, we suggest that Moshood's work could be partly analogous to this present study, in that, some specific morphological structures in Nzema proverbs are also anticipated to have basic or literal senses from which essential inferences could be made to understand the proverbs in general.

In exploring how women are perceived and representation in Bukusu and Gusii proverbs, Barasa \& Opande (2017) based their analysis on the assumptions of $\mathrm{CMT}^{1}$, proposed by Lakoff \& Johnson (1980), which sees metaphorical extensions as 'mappings' across two domains (from a source domain to a target domain), and discussed how certain animal attributions are transferred to describe the behaviour and nature of women from Bukusu and Gusii cultural context. The paper also deployed the FCDA, which relates to issues of gender, power and ideology. Using 48 animal-related proverbs which were purposively selected after interviewing five native respondents, the authors reinforce the dominant roles expected of men and the accompanying subdued roles of women as well as their vulnerability and weakness.

\footnotetext{
1 The following abbreviations are used in this paper: CDET (clausal determiner), CMT (conceptual metaphor theory), COMP (complementizer), COND (conditional marker), CONJ (conjunction), COP (copula verb), CPT (conditionality particle), DEF (definite article), EMPH.PT (emphatic particle), FCDA (feminist critical discourse analysis), FUT (future marker), HAB (habitual marker), IA (item-andarrangement), IP (item-and-process), NEG (negative marker), NOM (nominalising suffix), PAST (past marker), PERF (perfective marker), POSS (possessive marker), POST (postposition), PROG (progressive marker), RED (reduplicated morpheme), $1 \mathrm{PL}\left(1^{\text {st }}\right.$ person plural $), 1 \mathrm{SG}$ ( $1^{\text {st }}$ person singular $), 2 \mathrm{SG}$ ( $2^{\text {nd }}$ person singular $), 3 \mathrm{PL}$ ( $3^{\text {rd }}$ person plural), $3 \mathrm{SG}\left(3^{\text {rd }}\right.$ person singular).
} 
The paper revealed that proverbs in Bukusu and Gusii cultures relegate and compare women with pets, birds, farmyard animals, wild animals and inanimate objects. Women, according to the selected proverbs, are marginalised, discriminated in terms of decision making, participation, and are regarded as domestic workers and caregivers. They are perceived as inferior and subordinated to men.

Using Yankah's (1989) Theory of Proverbs Praxis, Yakub (2018) investigated the use of Nzema proverbs in appropriate context of communication to explicate the Nzema worldview of unity, togetherness and solidarity. The paper focused on proverbs that communicate the significance of cooperation and collaboration as a tool for success in performing a task. Data were obtained by interviewing four indigenous speakers of Nzema and reading of literary texts to select proverbs that were relevant to the study. The study also explored the appropriate contexts of use of the selected proverbs in Nzema discourse. Findings showed that the people of Nzema rely on proverbs to advocate the supremacy of group effort over individualism; stressing the essence of 'building' a communal traditional society. The paper concluded that Nzema proverbs are not cited randomly and haphazardly; rather, their employment and incorporation in any traditional speech event is 'context dependent'.

Owu-Ewie (2019) investigated the advisory role of proverbs in Akan (Fante). Employing the Relevance Theory, the study sought to explore the role of proverbs as a counselling tool in marriage contraction among the Akan, and to examine the pragmatic relevance and impact of Akan proverbs in the context of advising marriage couples. The study demonstrated that, during Akan traditional marriage contraction, the floor is opened at the latter part of the ceremony for optional speakers to offer series of advice in the context of 'enrolling' the couples onto the precious journey of marriage. In this regard, the study showed that the optional speakers deployed various Akan 
proverbs which highlighted themes such as cooperation, patience, hard-work, faithfulness, excessive friendship, heeding advice, emulating good behaviour, respect for each other, respect for in-laws, against violence, against sexual denial, against polygamy, provision of security and on child bearing. Owu-Ewie's work is quite appealing, fascinating and contributes significantly to the field of proverbial research. The pragmatic perspective from which the author analysed the data partly connects the present study and brings the two into some sort of resemblance; However, the current study focuses on the description of morphological structures in Nzema proverbs.

The above review provides some evidence that, across languages and cultures, studies on proverbs, and for that matter those undertaken from pragmatics perspective are enormous. However, Nzema seems to be given little attention in this regard. From the best of our knowledge, there is no study that looks at specific morphological properties that occur within the sentential structures of proverbs in Nzema, and how they contribute to the understanding of the proverbs. Further, the Ethnopragmatics and Morphological Models adopted for this discussion, partly renders it different from the previous studies which are grounded in the Relevance Theory, Critical Discourse Analysis Theory, CMT and the Theory of Proverbs Praxis. In essence, the current paper attempts to fill an essential gap, and to broaden the frontiers of the existing literature.

\section{Methodology}

Data for this qualitative study were obtained from primary and secondary sources. From the secondary source, we consulted a number of published works (literary texts in Nzema). One of these 
works is titled Nzema Mrele nee be Ngilenu by Kwesi \& Quarm (1998) which is a compilation of some traditional proverbs in Nzema. We found this material relevant because it contained most Nzema traditional proverbs, authored by competent native speakers. The other works (both novel and drama) in Nzema which were consulted are Hemans (1969), Ezenrane (1992), Kwaw (2012), and Soboh-Blay (2013). While reading these materials, we purposively selected proverbial structures and wrote them in a data collection notebook. In this endeavour, about thirty-five Nzema proverbs were handrecorded. The primary data involved a means of participant and nonparticipant observations. Some traditional gatherings and ceremonies such as marriage and arbitration were attended to fetch additional data, since these gatherings usually involve elders who use proverbs profusely in their communication. Through elicitation, we crosschecked the data and sought clarifications from native Nzema scholars. Having assembled about fifty proverbs in all, we selected and grouped them based on recurring morphological structures in the proverbial strings. Overall, twenty-four proverbs that are 'built' with interesting morphological properties like reduplication, inflections, derivations, borrowing and compounding were purposively considered for analysis in Section 5. The discussion focused on how these morphological structures could essentially contribute to the general interpretation and understanding of the proverbs. Introspections based on native speaker intuition were also significantly brought to bear on this study.

\section{Theoretical Framework}

The study combines two theoretical assumptions to guide the analysis. We adopt the Ethnopragmatics Model which deals with 
154 The Pragmatic Functions of Some Morphological Structures in Nzema Proverbs

understanding discourse from cultural-context to cater for the pragmatic interpretations in our discussion and also employ IA and IP Models which look at the arrangements and processes in morphological structures to underpin the morphological description. Some overviews of these frameworks are presented below in subsections 4.1 and 4.2 respectively.

\subsection{The Ethnopragmatics Model (Goddard 2006)}

Though pragmatic universalist over the years has gained dominance, a new pragmatic paradigm known as 'Ethnopragmatics' has refused to dash away (Goddard 2006). The basic tenet of Ethnopragmatics therefore maintains that speech practices are best understood from culture-internal perspective. It focuses on understanding discourse from the point of view of specific cultural perceptions, linguistic choices and communicative practices that are best conceived by a specific cultural group. In essence, discourse practices are best understood in terms which make sense to the cultural group concerned (Goddard 2006). Goddard (2006: 2) states that, "to understand and explicate the key ethnopragmatic concepts of another culture; However is no easy matter precisely because of their embeddedness within their own language". Largely, proverbs are a form of communicative device which are best conceived and understood from cultural context. Thus, we suggest that the morphological structures in the Nzema proverbs, since they are culturally constructed and incorporated within the proverbial structures, would contribute to the understanding of the proverbs based on the cultural values and worldview of the people of Nzema. The choice of the ethnopragmatic model as a theoretical underpinning for this study is therefore considered appropriate. 


\subsection{Item-and-Arrangement, Item-and Process (Hockett 1954)}

The paper is also underpinned by Hockett's (1954) two models of morphological description, popularly known as IA and IP. Hockett (1954) posits that IA entails clarifying what constitutes an item and what designates an arrangement, and the task is technically complex and not as easy as it sounds. In IA model, an utterance is considered as consisting of morphs which are arranged in certain manner connected and relative to one another. The IA model, as observed by Ajim (2018), concerns analysis of the structure of words by disintegrating or separating words into their immediate constituents. In other words, the model deals with the 'concatenated' nature of word-forms, such as affixation of bound morphemes onto a root/base in its simplest form. In the view of Booij (2010), this approach to analyzing morphologically complex words may be understood as "syntax of morphemes". Considering the word writers, we would assume that the constituents are arranged and formed through the concatenation of verbal base morpheme write as well as the NOM \{$\boldsymbol{e r}\}$ and the plural suffix $\{-\boldsymbol{s}\}$ that encode the meanings 'agent' and 'number' respectively (see also Lawer 2017: 52).

The IP model on the other hand holds that a word-form is the result of applying rules and processes that alter an existing word-form to generate a new one. According to Asiyanbola (2012) cited in Babalola (2021), the whole purpose of IP is directed towards explicating the process a specific root undergoes 'rather than representing a morpheme with a morph as captured in IA'. This can imply that IP does not seek to account for affixation; rather, under IP, different word formation processes are identified such as compounding, reduplication, conversion, coinage, blending, clipping, acronym, suppletion and even lexical borrowing which may not necessarily involve addition of a bound morpheme to a free/root morpheme. An interesting remark 
156 The Pragmatic Functions of Some Morphological Structures in Nzema Proverbs

about IP is that it clearly addresses the morphological transformation of irregular nouns and verbs with its idea of operation and process which has been analysed unsatisfactorily in IA model (Babalola 2021: 38). From the foregoing orientation, it could be observed that IA and IP together encompass and account for most word formation processes as morphological concepts. Therefore, the tenets of these two models (IA and IP) are also considered suitable for our analysis. The models will enable us account for, and adequately describe the various morphological operations and features that permeate the syntactic structure of the proverbs in this study.

\section{Data and Discussion}

In this section, we present and analyse the data. It is important to explicate the scope of the morphological discussions intended to be undertaken in this study since one may doubt the possibility of morphological analysis in the syntactic structure of proverbs. In the analysis, we do not consider all the words in a particular proverb for morphological analysis though almost every word in the proverb may be liable to morphological analysis. Instead, we highlight (bold) specific words that are 'paramount' in relation to their pragmatic inferences and how they enhance the overall interpretations of such proverbs. In other words, we explore the essence of the occurrence of such 'key' morphological features and how they contribute to the understanding of the entire concepts intended to be communicated in the proverbs.

\subsection{Reduplication}

Reduplication appears to be language universal inasmuch as 
countless languages of the world tend to operate it with identical grammatical functions and semantic readings (Abakah 2015). One of the interesting morphological features (word formation processes) that is prevalent in the structure of Nzema proverbs is the phenomenon of reduplication. Dolphyne (2006) describes reduplication as a type of word formation process which consists of the repetition of the whole or part of a stem. Reduplication indicates the recurrence of a morpheme either fully or partially (Hayes 2009). Ehineni (2017) contends that reduplication in Yorùbá can be total or full where all segments are completely copied, as in when wolé 'inspect house' becomes woléwolé 'house inspector'. Furthermore, "reduplication in Yorùbá can also be partial where only the initial consonant of a segment is reduplicated in the realized form" (Ehineni 2017: 42). In Nigerian Pidgin, for instance, as Babalola (2021: 40-41) remarks, "reduplication usually consists of the repetition of an entire lexical item or doubling of the entire base as in small small and fast fast". Marfo \& Osam (2018: 34) posit that "reduplication occurs in all the major word classes in Akan". In the morphology of Nzema also, the major lexical categories such as verbs, adverbs, adjectives and nouns can undergo reduplication which can be both total (full) and partial. In this study, however, as the data revealed, we look at reduplicated verbs and adverbs and examine their communicative roles as they manifest in the syntactic string of some proverbs in Nzema.

\subsubsection{Reduplicated Verbs in Nzema Proverbs}

In examples (1-6), the bolded verbal reduplicated forms have undergone complete reduplication. We examine the communicative contents of these reduplicated verbs as they occur in the structure of some proverbs in Nzema. 
158 The Pragmatic Functions of Some Morphological Structures in Nzema Proverbs

(1) Ale $\varepsilon$ mos $\varepsilon$-ke-li bie la $\varepsilon$-wuda-

food COMP 2SG-FUT-eat INDEF CDET 2SG-fan wuda 0 bo.

RED 3SG POST

'Rekindle the fire for cooking the food you intend to partake in its consumption.'

(Make continuous contribution towards something that you wish to benefit out of it.)

In example (1), the base verb wuda 'to rekindle' is reduplicated as wuda-wuda 'continue to rekindle' which is a total reduplication. This verb has been repeated in the construction to provide a crucial understanding of the proverb. The essence of reduplicating the verb actually informs us that one needs to make continuous effort and contribute towards something that he/she wishes to benefit out of it. The proverb teaches us to refrain from laziness and the habit of isolating ourselves; allowing our colleagues to struggle for us to enjoy the benefits later. It actually encourages collaborative efforts for mutual benefits in the end. It must be mentioned that the people of Nzema were largely and are still peasant subsistent farmers who go to the farm and come home with some firewood to prepare their food. Thus, it seems tangible for one to suggest that the proverb in (1) has some culture-internal background; emanating from the fact that firewoods that are used for cooking often need to be rekindled as in wuda$w u d a$. This makes it possible for us to conceptualise and interpret the proverb that 'one must make continuous effort to ensure the success of something that $\mathrm{s} /$ he wishes to benefit out of it'. 
(2) Saa m-gbanyinli kposa m-gbandu a n-gakula COND PL-elder chew PL-bottle CPT PL-child ne-ne nwole ebinli. shit-RED self faeces 'If elders chew bottles, the younger ones defecate repeatedly with blood content.'

(Future generations suffer the consequence of their forefathers' wrong deeds.)

In (2), the verb ne 'defecate' is reduplicated as in ne-ne 'defecate repeatedly'. The repeated morpheme makes it possible for us to best understand the proverb from the view point of 'cause and continuous effect'. In other words, the verb has been reduplicated to indicate that the younger generation rather suffer continuously should their elders indulge in any undesirable behaviour.

(3)

$\begin{array}{lllll}\text { Ekpote } & \text { di-di } & \text { fovole } & \text { zo } & \text { kpond } \varepsilon \\ \text { vulture } & \text { eat.HAB-RED } & \text { refuse.dump } & \text { POST } & \text { search } \\ \text { ngoane } & \text { tendenle. } & & & \\ \text { life } & \text { long } & & & \end{array}$

'The vulture continuously feeds on waste in order to live long.'

(One must continue to take precautions in life in order to live long.)

In (3) above, we observe that the base verb $d i$ 'to eat' has been iterated as in $d i-d i$ 'to eat repeatedly'. The vulture is noted for habitually feeding on carcass and other filthy and unwanted materials. It often enjoys these waste materials because it does not want to go near anything that is precious to mankind for the owner of such an 
item to harm it. This, in a way, helps the vulture to protect its life and live longer. Therefore, the purpose of repeating the verb in the proverbial structure is to enable us make the inference that we should continue to take precautions in life by always doing what would not lead us into predicaments. This is what pertains to the Nzema people.

$\begin{array}{lllll}\text { (4) Boane toa su-su } & \text { a } & \text { anrec } \\ \text { sheep follow } & \text { go.away-RED } & \text { CPT } & \text { SUBJ } \\ \text { o-n-li } & & \text { alec. } & & \\ \text { 3SG-NEG-eat } & \text { food } & & \end{array}$

'If the sheep were to care about continuous sacking, it would not have eaten.'

(Keep doing what you think is right despite any criticism against the act.)

In (4), $s u$ 'go/leave' has been totally reduplicated as in $s u$-su 'the act of driving away repeatedly'. The sheep (as the proverb portrays) keeps feeding on whatsoever feed it comes across and ignores the repeated effort by a person to prevent it from feeding because the sheep sees feeding as an obligation to sustain its life. The reduplicated form therefore occurs in the proverb as a specific morphological component that provides a semantic signal and so drives the hearer's understanding of the proverb to the fact that one must keep doing what is right, despite any criticisms against the act. 
$(5)$

$\begin{array}{llllll}\text { Saa } & \varepsilon \text { danle } & \text { te-te } & \text { a } & \text { be-fele } & \text { ye } \\ \text { COND } & \text { clothe } & \text { tear RED } & \text { CON.PT } & \text { 3PL-call } & \text { 3SG } \\ \text { fuazinli. } & & & & & \end{array}$

rag

'It is when a clothe is torn continuously, that it is considered to be a rag.'

(One must not give up in life because of initial failure unless there is persistent failure.)

In (5) above, the base verb te 'to tear' is fully copied as in te-te 'to tear continuously'. The verb is reduplicated to achieve the purpose of the proverb in the sense that, a clothe that is torn once may not necessarily be seen as a rag, rather, when it is torn repeatedly, it loses its value and then considered a rag. This implies that when one tries to do something for the first time, but does not succeed, it should not be taken as complete a failure until continuous efforts still do not materialise. The proverb seeks to instil perseverance in people.

(6) Saa $\varepsilon$-kye-kye a yec be-soa

COND 2SG-tie RED CPT then 3PL-help.carry

wo a.

2SG EMPH.PT

'If you continuously tie your load, others will help you to carry it.'

(One must make effort to prepare adequately for a task before seeking any assistance.)

In (6), the verb kye 'to tie' has been iterated as in kye-kye 'to tie repeatedly'. The repetition of the verb suggests continuous tie of one's load which is likened to one's readiness and adequate preparation to 
162 The Pragmatic Functions of Some Morphological Structures in Nzema Proverbs

undertake a task before seeking help from other people. The proverb advocates the essence of hardwork in terms of one's initial efforts to tackle a task. A summary of the reduplicated forms as discussed in (16) are illustrated below in Table 1:

Table 1. Verbal Reduplication in the Structure of Nzema Proverbs

\begin{tabular}{|l|c|}
\hline \multicolumn{1}{|c|}{ Base Verb } & Reduplicated Form \\
\hline a. wuda 'fan/rekindle' & wuda-wuda 'fan/rekindle continuously' \\
\hline b. ne 'defecate' & ne-ne 'defecate continuously' \\
\hline c. di 'eat' & di-di 'eat continuously' \\
\hline d. su 'go away' & su-su 'go away continuously' \\
\hline e. te 'tear' & te-te 'tear continuously' \\
\hline f. kye 'tie' & kye-kye 'tie continuously' \\
\hline
\end{tabular}

\subsubsection{Reduplicated Adverbs in Nzema Proverbs}

As Boakye (2015: 56) posits, some Akan adverbs, for instance, are able to undergo reduplication for the purpose of emphasising and describing the intensity of the action denoted by the verbs that the adverbs modify. Parallel to the functions of Akan reduplicated adverbs, Nzema adverbs are capable of undergoing reduplication to semantically indicate emphasis and intensity of the action being modified. The data revealed some instances of reduplicated adverbs in Nzema proverbs. Consider examples of this morphological phenomenon in (7-9): 
(7) Baka mos ke-wo be nye la tree COMP FUT-pierce 3PL.POSS eye CDET be-pe zole nde-nde. 3PL-cut POST quickly RED

'A stick that is capable of piercing ones eye must be cut very quickly.'

(One must quickly prevent circumstances that can bring about troubles.)

(8) Betec-betes a be-fa be-kye akowule slowly RED EMPH.PT 3PL-use 3PL-catch gnat a.

\section{EMPH.PT}

'One must act very slowly to be able to catch akowule (the gnat).'

(One needs to be patient in all endeavours.)

(9) Saa $\varepsilon$-tend $\varepsilon$

COND 2SG-talk

$$
\text { somaa-somaa }
$$$$
\text { a } \quad \varepsilon \text {-tia }
$$
$\varepsilon$ zebcla much-RED CPT 2SG-step agyake azo. 2SG in-law leg POST

'If you talk excessively, you step on the toes of your motherin-law.'

(Whoever talks so much always invites troubles for him/her self.)

In (7-9), the adverbs (bolded) in the structure of the proverbs have

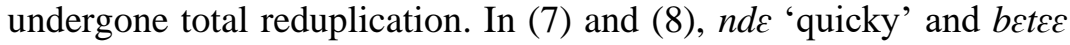
'slowly' are adverbs that are reduplicated as in $n d \varepsilon-n d \varepsilon$ 'very quickly'

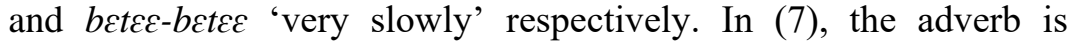


reduplicated to intensify/emphasize how quickly one must cut off a stick that is able to damage one's eye. This implies that one must immediately prevent any circumstance that is capable of causing harm. The proverb stands to speak against procrastination. In (8), the essence of the reduplicated adverb in the proverbial structure is to stress, and for that matter intensify how slowly one must make a move (in an attempt) to catch akowule 'the gnat' (a parasite which stings and sucks the blood of its host). The proverb tells us to be meticulous; being careful and patient in dealing with delicate issues. In (9), somaa 'much' is repeated as in somaa-somaa 'so much'. This repeated morpheme demonstrates the degree or amount of talking that is likely to make someone step on the toes of his mother-in-law. In Nzema culture, mother-in-law, for instance, is highly respected and so speaking ill to her is tantamount to stepping on her toes. The reduplicated adverb thus helps us to understand the proverb in the sense that, one who engages in excessive conversation, can make certain comments that can put him or her into trouble. The base adverbs and their respective reduplicated forms are represented below in Table 2:

Table 2. Reduplicated Adverbs in the Structure of Nzema Proverbs

\begin{tabular}{|c|c|}
\hline Base Adverb & Reduplicated Form \\
\hline a. nde 'quickly' & nd $\varepsilon$-nd $\varepsilon$ 'very quickly' \\
\hline b. beteq 'slowly' & 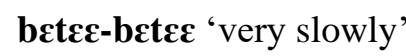 \\
\hline c. somaa 'much' & somaa-somaa 'so much' \\
\hline
\end{tabular}

\subsection{Inflectional Processes in the Structure of Nzema Proverbs}

Bound morphemes which signal grammatical categories such as tense, aspect, person, number, and negation are said to be inflectional 
(Mensah 2010). Ilori (2015: 55) opines that "plurals of animate nouns in Igálà grammar models are identified with two items, àm- and àb-, commonly analysed as plural affixes in the literature". In Nzema, prefixes such as $\{\mathbf{a}-, \mathbf{n}-, \mathbf{m}-, \mathbf{y}-\}$ are bound morphemes that are attached to base morphemes to indicate number. The suffixes $\{-\mathbf{m a}\}$ and $\{-\mathbf{l e}\}$ also indicate number and tense respectively in the morphology of Nzema. All these bound morphemes are class maintaining affixes which do not change the lexical categories of the root word they may be attached. In examples (10), (11) and (12), we show some inflectional processes in the structure of Nzema proverbs with $\{\mathbf{n}-, \mathbf{m}-, \mathbf{\eta}-\}$ as bound morphemes which indicate number.

(10) Anloma now n-deks le ye ngoane. bird self PL-feather COP 3SG.POSS life 'The feathers of a bird are its security.' (A king depends on his subjects for his security/strength.)

(11) Tunli nu m-boane le kpolane na pen POST PL-sheep COP group CONJ ewerne deda nu. boundary.PL exist POST

'A flock of sheep in a pen appear in a group but there are boundaries in-between.'

(People who constitute a clan/family actually come from individual mothers.)

(12) Saa kusu $\varepsilon$ n-le $\varepsilon$ k $\varepsilon$ a n-gila dwe. COND cat NEG-live there CPT PL-mouse rejoice 'When the cat is away, the mice rejoice.'

(When there is no authority, many people take the opportunity to misbehave.) 
166 The Pragmatic Functions of Some Morphological Structures in Nzema Proverbs

In (10-12), as can also be seen in Table 3 below, the bound morphemes $\{n-\},\{m-\}$ and $\{\mathrm{n}-\}$ are prefixed to the base nouns $\varepsilon d \varepsilon k \varepsilon$ 'feather', boane 'sheep' (singular) and kila 'mouse' respectively to obtain their plural counterparts as in $\boldsymbol{n} d \varepsilon k \varepsilon$ 'feathers', mboane 'sheep' and ygila 'mice' through homorganic nasal assimilation. In (10), $\boldsymbol{n} d \varepsilon k \varepsilon$ 'feathers' as a constituent in the proverbial structure has essentially inflected for number; in that, it helps us better understand that a king, for instance, uses his subjects for security. In (11), the inflectional process as in mboane 'sheep' (plural) informs us that, in any multitude of people, there are differences among them in terms of family, religion or ethnic background. In (12), the plural form ngila [ygila] 'mice' is significant in the structure for us to conceptualise that, not an individual, but many people (subordinates) take the advantage to rejoice and also misbehave whenever there is no authority or order. Table 3 further shows the internal structure of the words as highlighted in proverbs (10-12).

Table 3. Some Inflectional Processes in the Structure of Nzema Proverbs

\begin{tabular}{|c|c|c|}
\hline Base Noun (Singular) & Inflectional Prefix & Inflected Noun (Plural) \\
\hline a. $\varepsilon$ deke 'feather' & $\{\mathrm{n}-\}$ & $\underline{\text { nd} \varepsilon k \varepsilon \text { 'feathers' }}$ \\
\hline b. boane 'sheep' & $\{\mathrm{m}-\}$ & $\underline{\text { mboane 'sheep' }}$ \\
\hline c. kila 'mouse' & $\{\mathrm{n}-\}$ & ngila 'mice' \\
\hline
\end{tabular}

\subsection{Some Derivational Processes in the Structure of Nzema Proverbs}

Bound morphemes which result in the creation of new lexical categories from existing ones are known as derivational morphemes (Thakur 1997, Mensah 2010). In Nzema derivational processes, the 
suffixes $\{-$ vole $\}$ and $\{-n l i\}$ are identified as being able to change one lexical category to the other. The data for this study proved instances that some Nzema proverbs at the lexical level display a system of derivation. This occurs through the process of nominalization where a verb is converted to a noun by adding the NOM $\{-v o l \varepsilon\}$ to the root/base verbs as exemplified below in (13-15):

(13) Azule mos n-le ye kakye-vole la river COMP NEG-have 3SG remind-NOM CDET ati bo nyevile nu. head hit sea POST

'A river that does not have a reminder joins the sea.' (One who does not have a counsellor always encounters difficulties.)

(14) Boa-vole be-n-nyia ye. help-NOM 3PL-NEG-get 3SG

'It is not easy to find someone to offer you assistance.' (People who provide assistance to others are precious and difficult to come by.)

(15) Biza-vole $\varepsilon$ m-minli kpoke nu. interrogate-NOM NEG-lost forest POST 'One who seeks direction does not get lost in the forest.' (One who does not hesitate to seek information is always on top of issues.)

In (13-15), the words kakyevole 'reminder', boavole 'helper' and bizavole 'interrogator' are nouns with two morphemes each. The base verbs kakye 'remind' boa 'help' and biza 'interrogate' are suffixed by 
168 The Pragmatic Functions of Some Morphological Structures in Nzema Proverbs

the bound morpheme $\{-v o l \varepsilon\}$ to derive their nominalised counterparts respectively as can further be seen below in Table 4. Again, in (13), (14) and (15), such noun categories have been derived from the verbs because they exist in the proverbial structures to perform certain crucial roles such as reminding, helping and interrogating respectively which could not have been conceptualised if the verbal forms kakye 'remind' boa 'help' and biza 'interrogate' had rather been deployed in the construction of the proverbs without the NOM, $\{-v o l \varepsilon\}$. The internal components of these derivational processes are further shown in Table 4:

Table 4. Derivational Process (Verbal Nominalization) in Nzema Proverbs

\begin{tabular}{|c|c|c|}
\hline Base Verb & Nominalising Suffix & Derived Noun \\
\hline a. kakye 'remind' & $\{-\operatorname{vol} \varepsilon\}$ & kakyevole 'reminder' \\
\hline b. boa 'help' & $\{-\operatorname{vol} \varepsilon\}$ & boavole 'helper' \\
\hline c. biza 'interrogate' & $\{-$ vole $\}$ & bizavole 'interrogator' \\
\hline
\end{tabular}

We now turn to explore the prevalence of some borrowed words from English and Akan into Nzema proverbs, and to highlight their semantic and pragmatic imports.

\subsection{Lexical Borrowing in Nzema Proverbs}

Another word formation process that showcased in the data was the phenomenon of lexical borrowing. Some of the words in the proverbial structures were noted to have originated from different languages. These words are adopted and adapted to conform to the phonological system of Nzema, particularly in terms of syllable structure. The data specified words that are borrowed from English as 
well as Akan into the structure of Nzema proverbs which are discussed in turn under sections 5.4.1 and 5.4.2 respectively.

\subsubsection{Borrowed Words from English into Nzema Proverbs}

In examples (16), (17), (18) and (19) below, the bolded words patulo 'petrol', sigalcte 'cigarette', kale 'car', and pawoda 'powder' are borrowed from English to phonologically copy the Nzema sound system. The forms of these borrowed words in the proverbs actually follow the pronunciation of English though their sound patterns have been simplified to reflect a local 'flavour' (in the case of Nzema). These words are not just employed into the structure of some proverbs in Nzema, but can crucially contribute to the understanding of such proverbs in which they manifest. Some borrowed words from English were found in the data (Nzema proverbs) as exemplified in here:

(16) Patulo le ye nganec.

petrol has.POSS 3SG scent

'Petrol has its scent / petrol has a unique scent.'

(Everything has got its unique property/characteristic.)

In (16) for instance, the word patulo 'petrol' is borrowed into the proverb and described as having a unique scent. This holds true because petrol has a peculiar scent from other liquids such as kerosene, gasoline, palm oil, coconut oil and others. The Nzema believe that people have different destinies, though we are all human with similar physical or intellectual properties. Therefore, the imagery of petrol with a unique scent is likened to our real life situation, where every person or thing has distinctive characteristics to provide an outstanding mark of such a person or thing. The proverb exists to caution against greed and envy, so that people would not think 'evil' 
against prosperous people in the society.

(17)

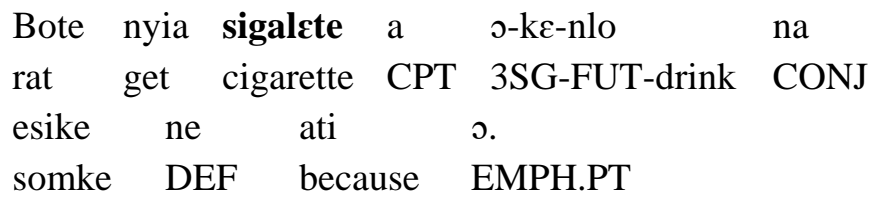

'The rat wishes to smoke cigarette, but it is deprived because of the 'smoke'.'

(One may wish to do something but certain conditions can prevent him/her.)

In (17) above, we encounter sigalcte 'cigarette' as a borrowed word in the proverbial structure. The literal meaning of the proverb suggests that 'the rat has the desire for cigarette smoking, but it is discouraged/ prevented because of the 'smoke' that comes out in the course of smoking'. Cigarette smoking is obviously accompanied by 'smoke', and the rat detests the presence of smoke especially in its habitat. This accounts for why the rat is often driven away from its habitat (hole) by setting fire around the hole in order to make the smoke enter its hole. This is metaphorically attributed to a situation where someone's social status or health condition prevents him/her from fulfilling his/her heart desires. A chief in Nzema culture, for instance, is normally deprived from playing games such as draught especially in public, though he may have the desire to play draught. This is so because of his status as a chief since there are certain invective utterances that accompany the playing of draught among the youth. 
(18) Kale ne mos $\varepsilon$-dwu zo la anwo car DEF COMP PERF-come new CDET same patulo $\varepsilon$-ra.

petrol PERF-come

'The kinds of cars that are available in these days have got petrol that befits them.'

(A particular situation at hand calls for its appropriate consequence.)

In (18), both kale 'car' and patulo 'petrol' have been adopted into the proverb. The proverb literally suggests that 'the kinds of cars that are available in these present days have got petrol that befits them'. The choice of kale 'car' represents a current situation/condition or somebody's attitude and way of life, whereas the choice of patulo 'patrol' in this context represents an appropriate result/consequence that is in order with such situation or deed. It simply underscores the fact that one gets the effect of what one does.

(19)

$\begin{array}{lrcll}\varepsilon \text {-kpond } \varepsilon & \text { tuck } & \text { anyiamgba } & \text { wo-abo } & \text { a } \\ \text { 2SG-want } & \text { hernia } & \text { disgrace } & \text { 2SG-cause } & \text { CON.PT } \\ \text { bia ye } & \text { bo } & \text { ye } & \text { pawoda. } & \end{array}$

bath 3SG apply 3SG powder

'If you want to put "inguinal hernia" into shame, bath it and apply powder on it.'

(You need to convince/persuade someone before he tells you about a top secret.)

In (19), pawoda 'powder' is borrowed to represent the sense of decorating something which may not originally look beautiful or pleasant. People living with "inguinal hernia" are quite not comfortable, 
and out of shyness would not want others to recognise them with such health conditions. The act of applying powder on the hernia is a way of decorating it, which would then make the carrier (patient) find it pleasant to avail it for public awareness. In this vein, pawoda 'powder' in the proverb is attributed or likened to using a fair means of persuading and convincing a person to reveal a secret. The proverb urges people to make proper use of their intelligence to solve problems.

\subsubsection{Borrowed Words from Akan into Nzema Proverbs}

Like the borrowed words from English, these words from Akan are also specific words that contribute to the understanding of such proverbs in which they are incorporated. In (20-22) that follow, we examine certain borrowed words from Akan into some Nzema proverbs as the data revealed.

(20) Koatelekoa se o-ke-maa wo $\varepsilon$ danl $\varepsilon$ clotheless.person say 3SG-FUT-give 2SG clothe a tie ye duma.

CPT hear 3SG name

'When a poor person promises to offer you a clothe, just consider his status.'

(We need not to rely on people who pledge to provide us what they themselves lack.) 

(21) Saa crelera butua wie a o-ko COND old.person buttocks finish CPT 3SG-go ababunlu dee nu. youth POSS POST 'If the buttocks of the elderly people get finished, they enter into that of the youth.'

(As the old people become weaker, the youth rather gain much strength.)

(22) Huhuhuhu dwu manone. rumours reach.HAB far places/countries 'A rumour spreads beyond other nations.' (Bad news quickly transcends boundaries for others to hear.)

In (20-22) above, the bolded words koatelekoa 'wealthless person', ababunlu 'youth' and manone 'far places' are borrowed words from Akan into the structures of such proverbs in Nzema, but are modified phonologically to conform to the sound system of Nzema. This is perhaps possible because Akan and Nzema are both Niger-Congo Kwa languages. In (20), for instance, a specific word that controls the understanding of the proverb is the borrowed word koatelekoa. Its literal meaning, 'wealthless person' is likened to a circumstance where somebody is absolutely poor. It therefore helps to understand that, a promise made by a needy person to provide someone with wealth, for instance, cannot be fulfilled. By this borrowed word in the proverb, we are informed not to remain idle and rely confidently on pledges, especially when the provider himself has unresolved challenges. In (21), ababunlu is adopted to literally represent 'the youth'. This helps to understand that, as the elderly people grow older and weaker, their thinking faculties, strength and ability to perform herculean tasks become the responsibilities of the youth (younger 
174 The Pragmatic Functions of Some Morphological Structures in Nzema Proverbs

generation). Like in many diverse societies, the Nzema frown at laziness, and so the youth are expected to be highly responsible, and to take over from the aged. In essence, the proverb entreats the youth to be up-and-doing. In (22), the borrowed word manone which literally means 'far places or across nations', helps us to understand the proverb in the sense that whenever there is a rumour (especially concerning undesirable issues), the message easily spreads beyond boundaries for many others to hear. The Nzema, thus, use the proverb to advise people to behave well in the society, since rumour about immorality quickly travels far places. The next discussion concentrates on compounding as a word formation process in the structure of some Nzema proverbs.

\subsection{Lexical Compounding in the Structure of Nzema Proverbs}

In the words of Shopen (2007: 24) "compounding involves wordformation based on the combination of at least two potentially free forms, most frequently members of open lexical classes such as nouns or verbs". Yule (2010: 55) also sees compounding as the process of combining two separate words to produce a single form. In the Nzema proverbs selected for this study, two instances of compound words showed up as part of the constituents structures such as follows:

(23) Sonla-mgbane $\varepsilon$ n-le ewiade.

person-useless NEG-exist world

'There is no useless person in the world.'

(Every creature in this universe has a purpose for its existence.) 


\section{(24) Ewule-kpolike sonla ko $\varepsilon$ n-vo. death-ladder person one NEG-climb \\ 'One person doesn't climb the ladder of death / death is inevitable to all mankind.' \\ (Every individual is likely to encounter a misfortune in the journey of life.)}

In (23), Sonlamgbane is a Noun + Adjective compound word, made up of a root noun sonla 'person' and a root adjective mgbane 'useless'. In this compound structure, the adjective qualifies the noun, thereby resulting in the gloss as 'useless person'. The entire essence and meaning of the proverb is chiefly dependent on this compound word sonlamgbane 'useless person'. This is because it serves as the 'key' word in the proverb from which referent is made to interpret the proverb that, everything in this world, whether human or nonhuman, in one way or the other has a significant reason for its existence/ occurrence. It further helps to derive the essence of the proverb, in that nothing happens without a purpose. In (24), ewulekpolike 'deathladder' is a Noun + Noun compound structure. The combination consists of the root nouns ewule 'death' and kpolike 'ladder'. In this compound structure, the former noun ewule 'death' modifies the latter kpolike 'ladder' to achieve the gloss as 'death-ladder' (a ladder made up of death). A better understanding of the proverb can be derived through this compound word ewulekpolike 'death-ladder' as the most 'vital' constituent in the structure and as a reference point to conceptualise that, death is inevitable in the life of man and that every individual is likely to encounter a misfortune in the journey of life. The proverb entreats people to recognise the adverse consequence of death, so as to be positive in all actions at all times. 


\section{Summary of Findings}

Relying on the theoretical thoughts of Ethnopragmatics and the Morphological Models-IA and IP, the paper explored the pragmatic relevance of some morphological structures in selected Nzema proverbs. The paper showed the prevalence of word formation processes, such as reduplication, inflections, derivations, lexical borrowing, and compounding in the construction of Nzema proverbs. This observation corroborates Mensah's (2010) position that proverbs, especially in the Efik language, exhibit great morphological features such as inflections, derivations, reduplication and lexical borrowing; occurring in the syntactic structures which underscore the agglutinative nature of the language. Interestingly, verbs are reduplicated in the proverbial structures to show both positive and negative effects of repeating certain actions in human existence. Adverbs are reduplicated in the structure of proverbs to intensify and lay emphasis on the advisory content of the proverb in terms of how and when an action should or should not be taken. The paper further showed the occurrence of the nasal consonants $\{\mathbf{n}-, \mathbf{m}-, \mathbf{y}\}$; which serve as inflectional prefixes attached to some noun constituents to indicate plurality in the proverbial structures. These inflectional processes help to communicate the essence of having a traditional society with 'multitude' of people for the purpose of security and hard-work. Words that are borrowed from English and Akan were also seen to prevail in some Nzema proverbs. These words essentially help to deduce the didactics and wisdom that are concealed in the proverbs, including the essence of positive attitudes such as perseverance and industriousness, avoiding greed and envy among others. 


\section{Conclusion}

In conclusion, it has come to light that the occurrences of some morphological processes in Nzema proverbs are pragmatically insightful, and not to be taken for granted. The culture and language made conscious incorporation of such morphological structures in the proverbial constructions in order to give a better understanding of the Nzema life, and to portray their philosophical principles and general worldview.

\section{References}

Abakah, E. 2015. On Tone and Morphophonology of Akan Reduplication Construction. Journal of Universal Language 16.1, $1-47$.

Adesina, L. 2015. Pragmatic Use of Some Proverbs on 'Egungun' among Yoruba Speakers. IOSR Journal of Humanities and Social Science 20.12, 1-6.

Ajim, S. 2018. Analysis of Derivational Processes in Tiv Morphology. M.A. Thesis, Benue State University.

Aku-Sika, C. 2016. Gendered Power Relations as Expressed in Selected Ewe Proverbs. M.Phil. Thesis, University of Ghana.

Almutalabi, M. \& A. Ameen. n.d. Exploring the Significance of Proverbs in English Language from a Pragmatic Perspective. Slemani: Cihan University.

Asiyanbola, A. 2012. Basic English Grammar for Universities: An Introduction. Lagos: Olivetree Publishing Venture.

Babalola, A. 2021. Morphological Features of Nigerian Pidgin in the Football Commentary. Journal of Universal Language 22.1, 27- 
178 The Pragmatic Functions of Some Morphological Structures in Nzema Proverbs

64.

Barasa, M. \& I. Opande. 2017. The Use of Animal Metaphors in the Representation of Women in Bukusu and Gusii Proverbs in Kenya. The Journal of Pan African Studies 10.2, 82-108.

Bhuvaneswar, C. 2012. The Syntax of Telugu Proverbs. Available at $<$ https://www.scribd.com/document/244386690/1-F1-ChilukuriBhuvaneswar-THE-SYNTAX-OFTELUGU-PROVERBS-1THE-SENTENCE-06-07-14-pdf >.

Boakye, B. 2015. Reduplication in Akan. M.A. Thesis, Norwegian University of Science and Technology.

Booij, G. 2010. Construction Morphology. Oxford: OUP.

Dolphyne, F. 2006. The Akan (Fante/Twi) Language: Its Sound Systems and Tonal Structure. 2nd edition. Accra: Black Mask Printing Press.

Ehineni, T. 2017. Prosodic Reduplication in Yorùbá. Journal of Universal Language 18.2, 39-59.

Ezenrane, N. 1992. cbelalekonle. Accra: Bureau of Ghana Languages.

Goddard, C. 2006. Ethno-pragmatics: A New Paradigm. Brisbane:

Griffith University.

Hayes, B. 2009. Introductory Phonology. Oxford: Blackwell.

Hemans, F. 1969. Adendule. Accra: Bureau of Ghana Languages.

Hockett, C. 1954. Two Models of Grammatical Description. Word 10.2-3, 210-234.

Ilọri, J. 2015. Plural Formation Strategies in Ígálà. Journal of Universal Language 16.1, 49-86.

Jegede, O. \& E. Osoba. 2019. The Pragmatics of Proverbs in Ola Rotimi's Kurunmi. Bulletin of Advanced English Studies 3.2, $92-$ 100.

Kwaw, F. 2012. Adwoba Ehwia. Accra: Literature and Cultural Research Bureau. 
Kwesi, G. \& P. Quarm. 1998. Nzema Mrele Nee Be Ngilenu. Accra: Bureau of Ghana Languages.

Lakoff, G. \& M. Johnson. 1980. Metaphors We Live By. Chicago, IL: University of Chicago Press.

Lamidi, M. 2008. The Structure and Texture of English Translations of Yorùbá and Igbo Proverbs. Journal of Universal Language 9.1, 61-90.

Lawer, R. 2017. Compounding in Dangme. M.A. Thesis, University of Ghana.

Marfo, C. \& E. Osam. 2018. Optimal Inflections as Asymmetry between Nominal and Verbal Reduplications in Akan. Ghana Journal of Linguistics 7.2, 33.

Mbiti, J. 1995. Children Confer Glory at Home: Introduction to the African Proverb Series. In M. Mokitimi (ed.), Proverbs of the Basotho. Ibadan: Daystar.

Mensah, E. 2010. A Morphosyntactic Analysis of Efik Proverbs. GLOSSA: An Interdisciplinary Journal 250-281.

Moshood, Z. 2016. A Pragmatic Analysis of Proverbs in Selected Works of Ola Rotimi. Ph.D. Dissertation, Ahmadu Bello University.

Nwankwo, O. 2015. Igbo Proverbs in the Context of Early Communicative Competence and Social Stability. Journal of Humanities and Social Science 20.9, 54-61.

Nyame, J. \& C. Tomekyin. 2018. Neological Developments in Nzema Proverbs. International Journal of Language \& Literature 6.2, 94-102.

Odebunmi, A. 2006. A Pragmatic Reading of Ahmed Yerima's Proverbs in Yemoja, Attahiru, and Dry Leaves on Ukan Trees. Intercultural Pragmatics 3.2, 153-169.

Owu-Ewie, C. 2019. Proverbs in Marriage: Counselling Role and 
180 The Pragmatic Functions of Some Morphological Structures in Nzema Proverbs

Implications. Legon Journal of the Humanities 30.1, 24-53.

Ramírez, C. 2015. A Pragmatic Approach to Proverb Use and Interpretation. Cadiz: Universidad de Cadiz.

Shopen, T. 2007. Language Typology and Syntactic Description. 2nd edition. Cambridge: CUP.

Soboh-Blay, A. 2013. Nyamenle Asa cnlomboc Ne. Accra: Bureau of Ghana Languages.

Sperber, D. \& D. Wilson. 1986. Relevance: Communication and Cognition. Oxford: Blackwell.

Sperber, D. \& D. Wilson. 1995. Relevance: Communication and Cognition. 2nd edition. Oxford: Blackwell.

Thakur, D. 1997. Linguistics Simplified: Morphology. Patna: Bharati Bhawan.

Yakub, M. 2018. Unity and Cooperation as Portrayed in Nzema Proverbs. International Journal of Linguistics and Literature 7.6, 43-56.

Yankah, K. 1989. The Proverb in the Context of Akan Rhetoric: A Theory of Proverb Praxis (Sprichwörterforschung). New York: Peter Lang.

Yule, G. 2010. The Study of Language. 4th edition. Cambridge: CUP. 